\title{
PREDICTORS OF CARDIAC CONDUCTION DISTURBANCES AFTER TRANSCATHETER AORTIC VALVE IMPLANTATION USING SELF- EXPANDABLE VALVES
}

\author{
Mahmoud Mohamed Baraka, Ahmad El-Sayed Yousef, \\ Diaa El-Din Ahmed Kamal, Maiy Hamdy El-Sayed.
}

\author{
Department of Cardiology, \\ Faculty of Medicine, Ain Shams \\ University, Cairo, Egypt \\ .Corresponding : \\ Mahmoud Mohamed Baraka \\ Mobile: 01015159338 \\ E mail: \\ mahmoudbaraka@hotmail.com
}

Received: 20/5/2019

Accepted: 18/6/2019

\begin{abstract}
:
Background: The advent of transcatheter aortic valve implantation (TAVI) represented a paradigm shift for treating patients with severe symptomatic aortic stenosis (AS) who are at high or prohibitive surgical risk. With the growing experience in this field, the rate of periprocedural complications has decreased over time and TAVI has been increasingly performed with a minimalist approach, evolving into a safe procedure with predictable outcomes. However, unlike other procedural complications, the incidence of conduction disturbances which could be in the form of bundle branch blocks, or atrioventricular blocks, has failed to decrease in recent times, with reports suggesting an increased risk associated with the use of some newer-generation transcatheter valves.
\end{abstract}

Aim of the work: To determine the predictors of cardiac conduction disturbances after transcatheter aortic valve implantation.

Patients and Methods: From January 2017 to April 2019, we included 38 consecutive patients with severe symptomatic AS underwent TAVI using self-expandable valves (CoreValve or Evolut $R$ ) or the balloon expandable Sapien XT valve at the Ain Shams University Hospitals. All patients were subjected to electrocardiographic evaluation pre- and post-TAVI and at 30 days. Several parameters were studied including preprocedural parameters: clinical, electrocardiographic, echocardiographic, and CT derived parameters, and procedural parameters: type and size of the valve, the use of balloon pre- and post- implantation dilatation, and depth of implantation. All quantitative parameters were indexed to body surface area (BSA).

Results: Conduction disturbances were seen in 16 patients (42.1\%), in which 10 patients (26.3\%) experienced left bundle branch block (LBBB), 6 patients (15.8\%) experienced complete heart block (CHB), with only one of them (2.6\%) experienced permanent CHB requiring permanent pacemaker implantation (PPI). Multivariate logistic regression analysis for pre-procedural predictors showed that the presence of basal septal calcification is the most powerful independent predictor (OR: 98.73, 95\% CI: 7.63 to 1278.23, p < 0.001). Multivariate logistic regression analysis for procedural predictors showed that the relationship between depth of implantation and membranous septum expressed in percentage (DIMS) with cut-off $>75.00 \%$ is the most powerful independent procedural predictor (OR: 16.00, 95\% CI: 2.12 to 120.65, $p$ 0.007). 
Conclusion: Conduction disturbances remain a common complication of TAVI. Presence of basal septal calcification is a risk factor that increase patient propensity for developing such complication after TAVI. The relationship between depth of implantation and membranous septum is a strong independent procedural predictor and prospective validation of its cut-offs is needed.

Key words: Transcatheter aortic valve implantation, conduction disturbances, AV blocks, LBBB.

\section{INTRODUCTION:}

Aortic valvular disease is a common disorder often affecting elderly patients with multiple co-morbidities. The most common type of aortic valvular disease today is senile calcific aortic stenosis $(\mathrm{AS})^{[1]}$. Despite vigorous efforts for developing medical treatment options for patients with calcific AS, medical therapy has currently no role in modifying the course of the disease, especially once symptoms or left ventricular dysfunction become manifest, and surgical aortic valve replacement (SAVR) remains the mainstay of definitive treatment ${ }^{[2]}$. However, and because AS is generally a disease of the elderly, co-morbidities are a frequent concern that may render patients inoperable. A percutaneous approach to aortic valve replacement is, therefore, an attractive alternative for many patients.

Percutaneous balloon aortic valvuloplasty has only a limited role in the treatment of calcific aortic stenosis, as the results are not durable ${ }^{[3]}$. On the other hand, transcatheter aortic valve implantation (TAVI) has shown great promise in the treatment of severe aortic stenosis in patients regarded at high risk from or inoperable by conventional surgery ${ }^{[4]}$. Since the first in man implantation by Alain Cribier in 2002 [5], TAVI has become a dynamic field of research and development.

Despite these benefits, a growing clinical experience with TAVI has revealed several intra- and post-procedure complications. One of these complications is the occurrence of post-operative conduction disturbances, the most relevant and common are His' bundle branch blocks, atrioventricular blocks, and need for permanent pacemaker implantation. With the frequency at $10 \%$ to even $50 \%$, conduction abnormalities are among the most important TAVI-related adverse events ${ }^{[6]}$.

\section{AIM OF THE WORK:}

To determine the predictors of cardiac conduction disturbances after TAVI, propose a predictive model that might modify the implantation technique to limit such complication.

\section{PATIENTS AND METHODS:}

Study was conducted from January 2017 to April 2019 at the Ain Shams University Hospitals. We included 39 consecutive patients with severe symptommatic AS defined as AVA $<1 \mathrm{~cm} 2$ or $<0.6$ $\mathrm{cm} 2 / \mathrm{m} 2$, with or without aortic regurgitation and have aortic valve annulus diameter $\geq 18$ and $\leq 29 \mathrm{~mm}$. Patients with previous pacemaker insertion, pre-existing LBBB, estimated life expectancy $<1$ year, active endocarditis, LV thrombus, excessive femoral, iliac or aortic tortuosity or calcification were excluded, one patient was excluded due to intra-operative mortality and postoperative ECG was not obtained, thus 38 patients were considered eligible for study. 
TAVI was done using self-expandable valves (CoreValve or Evolut $\mathrm{R}$ ) or the balloon expandable Sapien XT valve through femoral access using their corresponding sheaths and delivery systems. The procedure was performed with local anaesthesia in combination with a mild systemic sedative/analgesic treatment. Vascular access was obtained percutaneously through the common femoral artery (with or without pre-planned surgical cutdown according to availability of vascular closure devices at our center). At the start of each procedure, a temporary transvenous pacemaker was positioned in the right ventricle through transjugular or transfemoral access. This pacemaker remained in position for at least 24 hours after TAVI and was removed when there were no signs of AV block or bradycardia. Electrocardiographic outcomes were
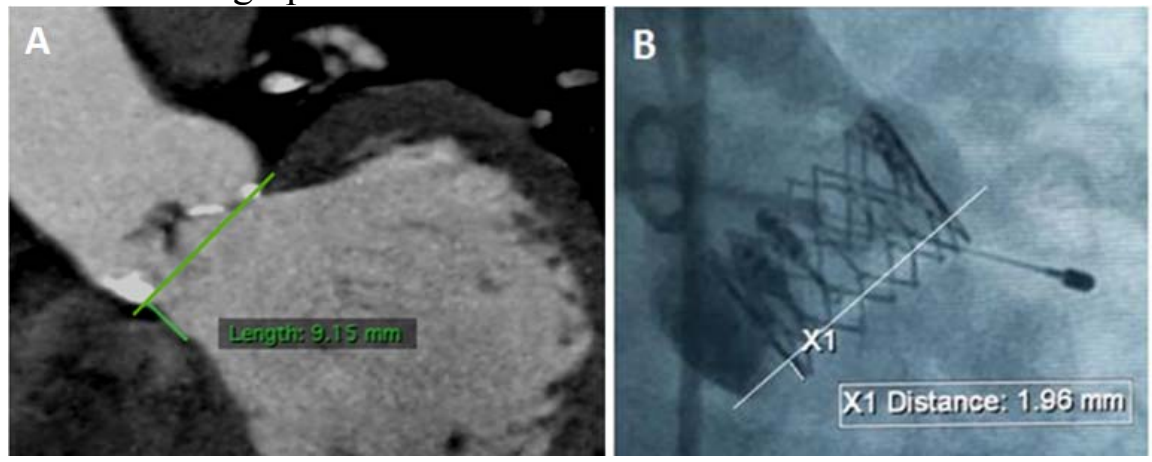

Figure: (A) CT coronal view showing measurement of membranous septum length, (B and C) Fluoroscopy views showing measurement of depth of implantation of Sapien XT and Evolut R valves respectively.

\section{RESULTS:}

The collected data were coded, tabulated, and statistically analyzed using IBM SPSS statistics (Statistical Package for Social Sciences) software version 18.0, IBM Corp., Chicago, USA, 2009. Conduction disturbances were seen in 16 patients (42.1\%), 10 patients $(26.3 \%)$ experienced LBBB, 6 patients (15.8\%) experienced AV block, with only one patient $(2.6 \%)$ experienced permanent $\mathrm{CHB}$ requiring permanent pacemaker implantation (PPI). Summary of the studied parameters, assessed continuously during the procedure. After the procedure, the patients were transferred to the intensive care unit for continuous monitoring of heart rhythm for average of 3 days.

Studied parameters were classified into pre-procedural and procedural parameters (see tables). The Pre-procedural parameters include clinical parameters, base line ECG parameters, echocardiographic parameters using GE Vivid machines, and CT-derived parameters using OsiriX MD v.9.0 (figure). Procedural parameters include type and size of the valve, the use of pre or postimplantation balloon dilatation, depth of implantation (DI), and relationship between depth of implantation and membranous septum which was expressed as numerical difference between them (MSID) or percentage (DIMS). 
other hand, the difference between MS and DI ( $\triangle$ MSID) showed highly significant negative correlation $(\mathrm{p}<0.001)$.

Table 1: Distribution of results and univariate analysis of clinical parameters

\begin{tabular}{|l|c|c|c|}
\hline \multicolumn{1}{|c|}{ Parameters } & $\begin{array}{c}\text { Present } \\
(\mathrm{N}=16)\end{array}$ & $\begin{array}{c}\text { Absent } \\
(\mathrm{N}=22)\end{array}$ & P Value \\
\hline Age (years) & $74.6 \pm 7.1$ & $76.3 \pm 7.3$ & $\dagger 0.463$ \\
\hline Body mass index $\left(\mathrm{kg} / \mathrm{m}^{2}\right)$ & $29.5 \pm 9.0$ & $27.6 \pm 3.4$ & $\dagger 0.437$ \\
\hline Body surface area $\left(\mathrm{m}^{2}\right)$ & $1.89 \pm 0.28$ & $1.87 \pm 0.19$ & $\dagger 0.817$ \\
\hline EuroSCORE II & $11.2 \pm 7.5$ & $9.1 \pm 6.7$ & $\dagger 0.357$ \\
\hline Creatinine clearance (ml/min) & $52.8 \pm 28.5$ & $53.1 \pm 23.2$ & $\dagger 0.964$ \\
\hline Male & $12(75.0 \%)$ & $16(72.7 \%)$ & $\varphi 1.000$ \\
\hline Smoking & $3(18.8 \%)$ & $8(36.4 \%)$ & $\varphi 0.296$ \\
\hline Diabetes Mellitus & $8(50.0 \%)$ & $12(54.5 \%)$ & $\phi 0.782$ \\
\hline Hypertension & $10(62.5 \%)$ & $16(72.7 \%)$ & $\phi 0.503$ \\
\hline Ischemic heart disease & $9(56.3 \%)$ & $12(54.5 \%)$ & $\phi 0.917$ \\
\hline Previous cerebrovascular stroke & $6(37.5 \%)$ & $9(40.9 \%)$ & $\phi 0.832$ \\
\hline CABG & $1(6.3 \%)$ & $3(13.6 \%)$ & $\varphi 0.624$ \\
\hline Chronic lung disease & $5(31.3 \%)$ & $7(31.8 \%)$ & $\phi 0.970$ \\
\hline Valve-in-Valve $(V i V)$ & $2(12.5 \%)$ & $0(0.0 \%)$ & $\varphi 0.171$ \\
\hline $\begin{array}{l}\dagger \text { Independent t-test, } \phi \text { Chi square test, } \varphi \text { Fisher's Exact test; CABG: coronary artery bypass } \\
\text { graft }\end{array}$ & & \\
\hline
\end{tabular}

Table 2: Distribution of results and univariate analysis of ECG and echocardiographic parameters

\begin{tabular}{|c|c|c|c|}
\hline Parameters & Present $(\mathrm{N}=16)$ & Absent $(\mathrm{N}=22)$ & $\mathrm{p}$ value \\
\hline \multicolumn{4}{|c|}{ ECG parameters } \\
\hline Atrial fibrillation (AF) & $4(25.0 \%)$ & $1(4.5 \%)$ & $\varphi 0.141$ \\
\hline RBBB & $5(31.3 \%)$ & $0(0.0 \%)$ & $\varphi 0.009^{*}$ \\
\hline PR interval duration (msec) & $198.3 \pm 21.2$ & $177.1 \pm 39.4$ & $\dagger 0.096$ \\
\hline QRS duration (msec) & $105.6 \pm 27.8$ & $88.6 \pm 8.3$ & $\dagger 0.030^{*}$ \\
\hline \multicolumn{4}{|c|}{ Echocardiographic Parameters } \\
\hline Ejection Fraction (\%) & $57.6 \pm 14.4$ & $60.0 \pm 13.4$ & $\dagger 0.595$ \\
\hline SWT (mm) & $13.9 \pm 2.2$ & $13.6 \pm 2.3$ & $† 0.674$ \\
\hline SWTi $(\mathrm{mm} / \mathrm{m} 2)$ & $7.4 \pm 1.0$ & $7.3 \pm 1.3$ & $\dagger 0.793$ \\
\hline PWT (mm) & $13.1 \pm 2.0$ & $12.7 \pm 1.7$ & $† 0.528$ \\
\hline LVEDD $(\mathrm{mm})$ & $52.3 \pm 6.1$ & $53.1 \pm 6.5$ & $\dagger 0.695$ \\
\hline LVEDDi $(\mathrm{mm} / \mathrm{m} 2)$ & $28.1 \pm 3.9$ & $27.7 \pm 7.6$ & $\dagger 0.851$ \\
\hline LVESD (mm) & $34.1 \pm 7.2$ & $35.0 \pm 7.8$ & $† 0.694$ \\
\hline LVESDi (mm/m2) & $18.3 \pm 4.5$ & $19.0 \pm 5.2$ & $\dagger 0.705$ \\
\hline Mean pressure gradient $(\mathrm{mmHg})$ & $49.4 \pm 6.9$ & $51.9 \pm 14.0$ & $† 0.510$ \\
\hline Aortic valve area $(\mathrm{cm})$ & $0.80 \pm 0.17$ & $0.78 \pm 0.14$ & $\dagger 0.662$ \\
\hline AR grade III & $6(37.5 \%)$ & $2(9.1 \%)$ & $\varphi 0.049^{*}$ \\
\hline
\end{tabular}


Table 3: Distribution of results and univariate analysis of CT-derived parameters

\begin{tabular}{|c|c|c|c|}
\hline Findings & Present $(\mathrm{N}=16)$ & Absent $(\mathrm{N}=22)$ & $\mathrm{p}$ value \\
\hline Annulus mean diameter & $23.1 \pm 3.1$ & $24.1 \pm 1.9$ & $\dagger 0.274$ \\
\hline Annulus mean diameter indexed $\left(\mathrm{mm} / \mathrm{m}^{2}\right)$ & $12.4 \pm 2.0$ & $13.0 \pm 1.4$ & $\dagger 0.340$ \\
\hline Annulus perimeter & $7.3 \pm 0.9$ & $7.7 \pm 0.6$ & $\dagger 0.085$ \\
\hline Annulus perimeter indexed $\left(\mathrm{mm} / \mathrm{m}^{2}\right)$ & $3.9 \pm 0.6$ & $4.1 \pm 0.5$ & $\dagger 0.201$ \\
\hline Annulus area & $4.0 \pm 1.0$ & $4.5 \pm 0.7$ & $\dagger 0.124$ \\
\hline Annulus area $\mathrm{I}\left(\mathrm{mm} / \mathrm{m}^{2}\right)$ & $2.2 \pm 0.5$ & $2.4 \pm 0.4$ & $\dagger 0.123$ \\
\hline LMCA & $12.5 \pm 1.2$ & $13.4 \pm 2.2$ & $\dagger 0.081$ \\
\hline LMCAi $\left(\mathrm{mm} / \mathrm{m}^{2}\right)$ & $6.7 \pm 1.1$ & $7.2 \pm 1.2$ & $\dagger 0.206$ \\
\hline $\mathrm{RCA}$ & $13.7 \pm 2.0$ & $13.7 \pm 2.9$ & $\dagger 0.981$ \\
\hline $\mathrm{RCAi}\left(\mathrm{mm} / \mathrm{m}^{2}\right)$ & $7.4 \pm 1.2$ & $7.4 \pm 1.6$ & $\dagger 0.982$ \\
\hline MS & $7.1 \pm 1.9$ & $8.1 \pm 2.9$ & $\dagger 0.211$ \\
\hline $\mathrm{MSi}\left(\mathrm{mm} / \mathrm{m}^{2}\right)$ & $3.8 \pm 1.1$ & $4.4 \pm 1.7$ & $\dagger 0.228$ \\
\hline Basal septal calcification & $14(87.5 \%)$ & $2(9.1 \%)$ & $\phi<0.001^{*}$ \\
\hline Aortic valve calcification grade IV & $11(68.8 \%)$ & $12(54.5 \%)$ & $\phi 0.376$ \\
\hline \multicolumn{4}{|c|}{$\begin{array}{l}\text { Independent t-test, } \phi \text { Chi square test, * significant } \\
\text { LMCA: left main coronary artery; RCA: right coronary artery; MS and MSi: length of membranous septum and } \\
\text { indexed value. }\end{array}$} \\
\hline
\end{tabular}

Table 4: Distribution of results and univariate analysis of procedural parameters

\begin{tabular}{|c|c|c|c|c|}
\hline \multicolumn{2}{|r|}{ Characteristics } & Present & Absent & $\mathrm{p}$ \\
\hline \multirow[t]{5}{*}{ Valve type } & CoreValve & $2(12.5 \%)$ & $1(4.5 \%)$ & \multirow[t]{3}{*}{$\varphi 0.287$} \\
\hline & Evolut R & $12(75.0 \%)$ & $13(59.1 \%)$ & \\
\hline & Sapien XT & $2(12.5 \%)$ & $8(36.4 \%)$ & \\
\hline & Self-expandable valves & $14(87.5 \%)$ & $14(63.6 \%)$ & \multirow[t]{2}{*}{$\varphi 0.143$} \\
\hline & Balloon-expandable valves & $2(12.5 \%)$ & $8(36.4 \%)$ & \\
\hline \multicolumn{2}{|c|}{ Balloon predilatation } & $2(12.5 \%)$ & $10(45.5 \%)$ & $\phi 0.131$ \\
\hline \multicolumn{2}{|c|}{ Balloon Postdilatation } & $5(31.3 \%)$ & $2(9.1 \%)$ & $\& 0.108$ \\
\hline \multicolumn{2}{|c|}{ Valve size $>29 \mathrm{~mm}$} & $9(56.3 \%)$ & $13(59.1 \%)$ & $\phi 0.861$ \\
\hline \multicolumn{2}{|c|}{ Depth of implantation (mm) } & $7.1 \pm 1.8$ & $3.7 \pm 1.6$ & $\dagger<0.001 *$ \\
\hline \multicolumn{2}{|c|}{ Depth of implantation indexed $\left(\mathrm{mm} / \mathrm{m}^{2}\right)$} & $3.8 \pm 1.1$ & $2.0 \pm 0.8$ & $\dagger<0.001 *$ \\
\hline \multicolumn{2}{|c|}{ DIMS } & $101.5 \pm 17.9$ & $49.2 \pm 17.2$ & $\dagger<0.001 *$ \\
\hline \multicolumn{2}{|l|}{$\Delta \mathrm{MSID}$} & $0.1 \pm 1.1$ & $4.4 \pm 2.5$ & $\dagger<0.001 *$ \\
\hline \multicolumn{5}{|c|}{$\begin{array}{l}\dagger \text { Independent t-test, } \phi \text { Chi square test, } \varphi \text { Fisher's Exact test, } * \text { significant } \\
\text { DIMS: percentage of depth of implantation from membranous septum; } \Delta \text { MSID: difference between } \\
\text { membranous septum and implantation depth }\end{array}$} \\
\hline
\end{tabular}

Among the studied parameters, it has been found that basal septal calcification was the best preprocedural predictor of development of conduction disturbances after TAVI with sensitivity $87.5 \%$, and specificity $90.9 \%$. And that DIMS with cut off $\geq 75.00 \%$, and $\Delta$ MSID with cut off $\leq 1.75$ $\mathrm{mm}$ are the best postprocedural predictors with sensitivity $100 \%$, and specificity $95.5 \%$ as shown in table 5 . 
Table 5: Diagnostic performance of the significant parameters in predicting conduction abnormalities

\begin{tabular}{|l|c|c|c|c|c|}
\hline \multicolumn{1}{|c|}{ Factors } & AUC & SE & P & $95 \%$ CI & Cut off \\
\hline QRS width & 0.658 & 0.100 & 0.101 & $0.462-0.854$ & -- \\
\hline DI & 0.909 & 0.047 & $<0.001^{*}$ & $0.814-1.000$ & $\geq 4.87$ \\
\hline DIi & 0.909 & 0.047 & $<0.001^{*}$ & $0.817-1.000$ & $\geq 2.30$ \\
\hline DIMS & 0.996 & 0.006 & $<0.001^{*}$ & $0.000-1.000$ & $\geq 75.00$ \\
\hline$\Delta$ MSID & 0.994 & 0.008 & $<0.001^{*}$ & $0.000-1.000$ & $\leq 1.75$ \\
\hline
\end{tabular}

AUC: Area under curve, SE: Standard error, CI: Confidence interval, *significant

DI: depth of implantation; DIi: depth of implantation indexed; DIMS: percentage of DI of membranous

septum (MS); $\triangle$ MSID: difference between MS and DI

Variables with $\mathrm{p}$ values $<0.1$ on univariate analysis were entered into 2 multivariate logistic regression models: Preprocedural prediction model and procedural prediction model. Basal septal calcification emerged as the most powerful independent preprocedural predictor of conduction disturbances, while the procedural prediction model revealed DIMS $\geq 75.00 \%$ as the most powerful independent procedural predictor (table 6).

Table (6): Multivariate logistic regression analysis models

\begin{tabular}{|l|c|c|c|c|}
\hline \multicolumn{1}{|c|}{ Parameters } & $\beta$ & SE & P & OR (95\% CI) \\
\hline \multicolumn{5}{|c|}{ Preprocedural model } \\
\hline Basal septal calcification & 4.59 & 1.31 & $<\mathbf{0 . 0 0 1 *}$ & $98.73(7.63-1278.23)$ \\
\hline \multicolumn{4}{|c|}{ Procedural model } \\
\hline DIMS $\geq 75.00 \%$ & 2.77 & 1.03 & $\mathbf{0 . 0 0 7}$ & $16.00(2.12-120.65)$ \\
\hline $\begin{array}{l}\beta \\
\text { p: Regression coefficient; SE: Standard error; OR: Odds ratio; CI: Confidence interval; *significant; DIMS: } \\
\text { percentage of DI of membranous septum }\end{array}$
\end{tabular}

\section{DISCUSSION}

Whilst efforts to reduce the incidence of complications after TAVI have generated improvements in valve technology with a substantial reduction of their severity and their clinical impact ${ }^{[7-9]}$, the development of conduction disturbances after TAVI has failed to decrease significantly in recent times with reports suggesting an increased risk associated with the use of some newergeneration valves ${ }^{[10-15]}$.

Previous studies have showed that the most encountered conduction disturbances after TAVI are the new onset LBBB which occurs in up to $50-70 \%$ (with a wide range of $25 \%$ to $85 \%$ after implantation of the CoreValve system and from $8 \%$ to $30 \%$ after the implantation of a Edwards Sapien valves), and third-degree AV block with a subsequent need for PPI ranging from $5.7 \%$ to $42.5 \%$ (with a median of $28 \%$ for the Medtronic CoreValve System and 6\% for the Edwards Sapien valves) ${ }^{[16-22]}$.

Incidence of conduction disturbances in our study was $26.3 \%$ for new onset LBBB (28.6\% for the CoreValve system, and 20\% for Sapien XT), and the incidence of complete heart block was $15.8 \%$ (21.4\% for the CoreValve system, and absent with Sapien XT). These results match the international rates, putting in consideration the relatively small study population especially with Sapien XT.

As regards the procedural -modifiablerisk factors and depth of implantation, a Spanish study ( $\mathrm{n}=65$; CoreValve only) reported a frame depth in the LVOT of 11.1 $\mathrm{mm}$ as an independent predictor of PPI with 
$81 \%$ sensitivity and $84.6 \%$ specificity ${ }^{[23]}$. Similarly, another study revealed that if the proximal end of the valve frame was positioned $<6.7 \mathrm{~mm}$ from the lower edge of the noncoronary cusp, no prosthesis-related left bundle branch block would occur ${ }^{[24]}$.

The new repositionable Evolut $\mathrm{R}$ offers potential benefits compared to the preceding CoreValve. A study by Giannini, C., et al. ${ }^{[25]}$ comparing the performance of the Evolut $\mathrm{R}$ with the CoreValve showed that the recapture and reposition maneuvers allowed a less implantation depth for the Evolut R, and as a consequence, the rate of PPI was lower in patients receiving the Evolut $\mathrm{R}$. The manufacturer recommends optimal DI between $4-6 \mathrm{~mm}$ for the CoreValve and 3 $5 \mathrm{~mm}$ for the Evolut R.

As regard the Sapien prosthesis, Urena, M., et al ${ }^{[26]}$ demonstrated that new-onset LBBB correlated with DI and each 1-mm increase in the DI corresponded to a 1.37 increase in the odds ratio for developing new LBBB.

Our study has reached a cut-off of DI $\geq$ $4.87 \mathrm{~mm}$ to be a strong predictor of conduction disturbances after TAVI with sensitivity $93.8 \%$, and specificity $81.8 \%$. Moreover, indexed DI (DIi) was shown to have a strong predictive ability and that a cut-off of DIi $\geq 2.30 \mathrm{~mm} / \mathrm{m}^{2}$ had sensitivity of $93.8 \%$ and specificity $72.7 \%$ in predicting conduction disturbances after TAVI. To the best of our knowledge, DIi has not been studied before and further studies are needed for verification.

Studying the relationship between depth of implantation (DI) and membranous septum length (MS) was the core of our study. This relationship was previously studied and expressed as the numerical difference between them ( $\triangle$ MSID) in a study $(\mathrm{N}=73)$ by Hamdan, A., et al. ${ }^{[2]}$ using self expandable valves, $\triangle$ MSID was shown to be the strongest independent procedural predictor of high degree AV block (OR: 1.4,
95\% CI: 1.2 to $1.7, \mathrm{p}<0.001)$. Furthermore, he reached a cut-off of $\triangle$ MSID of $0.4 \mathrm{~mm}$ to be able to predict high degree AV block with sensitivity $92.3 \%$, specificity $76.7 \%$ and negative predictive value (NPV) close to $97.8 \%$.

Our study has shown that $\triangle \mathrm{MSID}$ is a strong predictor of conduction disturbances after TAVI $(\mathrm{p}<0.001)$ and we reached a cutoff of $\leq 1.75 \mathrm{~mm}$ to be a strong procedural predictor of conduction disturbances with sensitivity reaching $100 \%$, specificity $95.5 \%$, and NPV 100\%. The difference between cut-offs may be attributed to different study populations.

However, this was opposed in a study ( $n=61$; Sapien 3 only) by Oestreich, B., et al. [28] showing that neither the MS nor $\Delta$ MSID, predicts conduction disturbance ( $\mathrm{p}=$ 0.09 , and 0.64 respectively) and that only DI and basal septal calcification are the strongest predictors of conduction disturbances $\quad(p=0.02, \quad$ and 0.04 respectively). In concordance with this study, we also concluded that MS is not a predictor $(p=0.211)$ but we found that $\triangle \mathrm{MSID}$ is a strong procedural predictor. This difference in results could be attributed to different valves used.

Moreover, we expressed the relationship between DI and MS in the form of percentage (DIMS) which also turned out to be a strong predictor $(\mathrm{p}<0.001)$, and that a cut-off $\geq 75.00 \%$ is a strong procedural predictor with the same predictive power as $\Delta$ MSID. On applying multivariate regression analysis for procedural predictors, DIMS emerged as the most powerful independent procedural predictor (OR: $16.00,95 \%$ CI: 2.12 to 120.65 , p 0.007). We are proposing that expressing this relationship in the form of percentage rather than numerical difference in millimetres might be more practical and easier for use especially in situations in which the membranous septum length is short, at that point estimating and foreword planning the 
DI in percentage will be more convenient and feasible.

As regards preprocedural predictors, our study concluded that basal septal calcification is a strong predictor of conduction disturbances $(\mathrm{p}=0.001)$, and when applying multivariable logistic regression for the pre-procedural predictors, the basal septal calcification emerged as the most powerful independent preprocedural predictor of conduction disturbances (OR: 98.73, 95\% CI: 7.63 to $1278.23, \mathrm{p}<0.001)$. These results are in concordance with Hamdan, A., et al. ${ }^{[27]}$ who also concluded that basal septal calcification is a strong independent predictor (OR: 4.9, 95\% CI: 1.2 to $20.5, \mathrm{p}=0.031$ ). Similarly, A study $\left(\mathrm{N}=81\right.$; CoreValve) by Latsios, G., et al. ${ }^{[29]}$ has found basal septal calcification as the most powerful independent predictor of conduction disturbances (OR: 1.06, 95\% CI: 1.02-1.11, p 0.004). This could be attributed to the fact that the presence of calcium at the basal interventricular septum could result in direct injury to the conduction system when it is sandwiched between the valve frame and the septum.

\section{Conclusion:}

Conduction disturbances remain a common complication of TAVI. Presence of basal septal calcification is a risk factor that increase patient propensity of development such complication after TAVI. The relationship between depth of implantation and membranous septum is a strong independent procedural predictor and prospective validation of its cut-offs is needed.

\section{Limitation:}

This study was a single-center observational non randomized study with all its inherent limitations, most importantly the relatively small study population. Larger size valves (CoreValve 31/34) were rarely used due to availability at the time of our study. Presence of basal septal calcification was included qualitatively rather than graded or quantified.

\section{REFERENCES:}

1. Otto, C.M., et al., Association of aorticvalve sclerosis with cardiovascular mortality and morbidity in the elderly. $\mathrm{N}$ Engl J Med, 1999. 341(3): p. 142-7.

2. Vahanian, A., et al., [Guidelines on the management of valvular heart disease (version 2012). The Joint Task Force on the Management of Valvular Heart Disease of the European Society of Cardiology (ESC) and the European Association for CardioThoracic Surgery (EACTS)]. G Ital Cardiol (Rome), 2013. 14 (3): p. 167-214.

3. Iung, B., et al., A prospective survey of patients with valvular heart disease in Europe: The Euro Heart Survey on Valvular Heart Disease. Eur Heart J, 2003. 24(13): p. 1231-43.

4. Grube, E., et al., Percutaneous implantation of the CoreValve self-expanding valve prosthesis in high-risk patients with aortic valve disease: the Siegburg first-in-man study. Circulation, 2006. 114(15): p. 161624.

5. Cribier, A., et al., Percutaneous transcatheter implantation of an aortic valve prosthesis for calcific aortic stenosis: first human case description. Circulation, 2002. 106 (24): p. 3006-8.

6. Urena, M., et al., Permanent pacemaker implantation after transcatheter aortic valve implantation: impact on late clinical outcomes and left ventricular function. Circulation, 2014. 129(11): p. 1233-43.

7. Reinohl, J., et al., Effect of Availability of Transcatheter Aortic-Valve Replacement on Clinical Practice. N Engl J Med, 2015. 373(25): p. 2438-47.

8. Vahl, T.P., S.K. Kodali, and M.B. Leon, Transcatheter Aortic Valve Replacement 2016: A Modern-Day "Through the Looking-Glass" Adventure. J Am Coll Cardiol, 2016. 67(12): p. 1472-1487. 
9. Babaliaros, V., et al., Comparison of transfemoral transcatheter aortic valve replacement performed in the catheterization laboratory (minimalist approach) versus hybrid operating room (standard approach): outcomes and cost analysis. JACC Cardiovasc Interv, 2014. 7(8): p. 898-904.

10. De Torres-Alba, F., et al., Changes in the Pacemaker Rate After Transition From Edwards SAPIEN XT to SAPIEN 3 Transcatheter Aortic Valve Implantation: The Critical Role of Valve Implantation Height. JACC Cardiovasc Interv, 2016. 9(8): p. 805-813.

11. Husser, O., et al., Predictors of Permanent Pacemaker Implantations and New-Onset Conduction Abnormalities With the SAPIEN 3 Balloon-Expandable Transcatheter Heart Valve. JACC Cardiovasc Interv, 2016. 9(3): p. 244-254.

12. Meredith Am, I.T., et al., Transcatheter aortic valve replacement for severe symptomatic aortic stenosis using a repositionable valve system: 30-day primary endpoint results from the REPRISE II study. J Am Coll Cardiol, 2014. 64(13): p. 1339-48.

13. Schofer, J., et al., Prospective multicenter evaluation of the direct flow medical transcatheter aortic valve. J Am Coll Cardiol, 2014. 63(8): p. 763-8.

14. Silaschi, M., et al., The JUPITER registry: 1-year results of transapical aortic valve implantation using a second-generation transcatheter heart valve in patients with aortic stenosis. Eur J Cardiothorac Surg, 2016. 50(5): p. 874-881.

15. Seiffert, M., et al., Single-centre experience with next-generation devices for transapical aortic valve implantation. Eur $\mathrm{J}$ Cardiothorac Surg, 2015. 47(1): p. 39-45; discussion 45.

16. Kodali, S.K., et al., Two-year outcomes after transcatheter or surgical aortic-valve replacement. N Engl J Med, 2012. 366(18): p. 1686-95.

17. Zahn, R., et al., Transcatheter aortic valve implantation: first results from a multi- centre real-world registry. Eur Heart J, 2011. 32(2): p. 198-204.

18. Grube, E., et al., Percutaneous aortic valve replacement for severe aortic stenosis in high-risk patients using the second- and current third-generation self-expanding CoreValve prosthesis: device success and 30-day clinical outcome. J Am Coll Cardiol, 2007. 50(1): p. 69-76.

19. Webb, J.G., et al., Percutaneous aortic valve implantation retrograde from the femoral artery. Circulation, 2006. 113(6): p. 842-50.

20. Bates, M.G., et al., Postoperative permanent pacemaker implantation in patients undergoing trans-catheter aortic valve implantation: what is the incidence and are there any predicting factors? Interact Cardiovasc Thorac Surg, 2011. 12(2): p. 243-53.

21. Karyofillis, P., et al., Conduction abnormalities after transcatheter aortic valve implantation. J Geriatr Cardiol, 2018. 15(1): p. 105-112.

22. Auffret, V., et al., Conduction Disturbances After Transcatheter Aortic Valve Replacement: Current Status and Future Perspectives. Circulation, 2017. 136(11): $\mathrm{p}$. 1049-1069.

23. Munoz-Garcia, A.J., et al., Changes in atrioventricular conduction and predictors of pacemaker need after percutaneous implantation of the CoreValve(R). Aortic valve prosthesis. Rev Esp Cardiol, 2010. 63(12): p. 1444-51.

24. Piazza, N., et al., Early and persistent intraventricular conduction abnormalities and requirements for pacemaking after percutaneous replacement of the aortic valve. JACC Cardiovasc Interv, 2008. 1(3): p. 310-6.

25. Giannini, C., et al., Transcathether aortic valve implantation with the new repositionable self-expandable Evolut $R$ versus CoreValve system: A case-matched comparison. Int J Cardiol, 2017. 243: p. 126-131. 


\section{Mahmoud Mohamed Bara, et al.,}

26. Urena, M., et al., Predictive factors and long-term clinical consequences of persistent left bundle branch block following transcatheter aortic valve implantation with a balloon-expandable valve. J Am Coll Cardiol, 2012. 60(18): p. 1743-52.

27. Hamdan, A., et al., Inverse Relationship Between Membranous Septal Length and the Risk of Atrioventricular Block in Patients Undergoing Transcatheter Aortic Valve Implantation. JACC Cardiovasc Interv, 2015. 8(9): p. 1218-1228.
28. Oestreich, B., et al., Calcification in the basal septum, but not membranous septal length, predicts $A V$ conduction disturbance and pacemaker implantation following transcatheter aortic valve replacement with a balloon-expandable valve (S3). Journal of the American College of Cardiology, 2017. 69(11 Supplement): p. 1239.

29. Latsios, G., et al., "Device landing zone" calcification, assessed by MSCT, as a predictive factor for pacemaker implantation after TAVI. Catheter Cardiovasc Interv, 2010. 76(3): p. 431-9. 


\section{المتنبئات لحدوث اضطرابات في التوصيل الكهربائي بالقلب بعد زرع الصمام الأورطي بواسطة

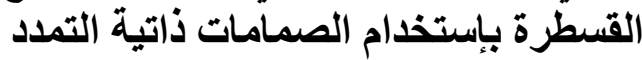 \\ محمود محمد علي بركه ،أحمد السيا يوسف ،ضياء الدين أحمد كمال،مي حمدي السيد \\ قسم القلب ،كلية الطب،جامعة عين شمس،القاهرة،مصر}

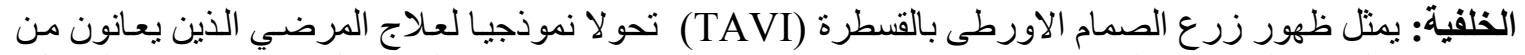

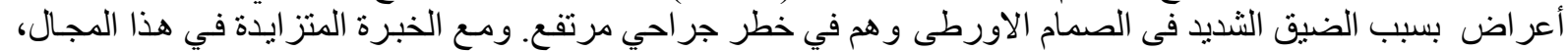

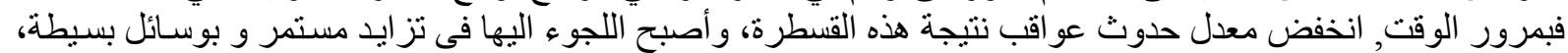

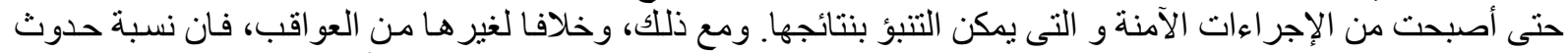

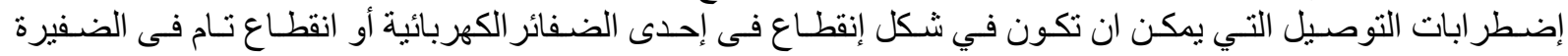

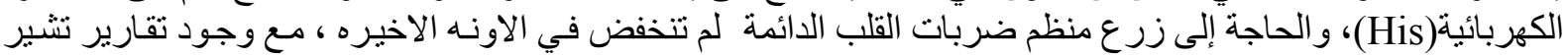

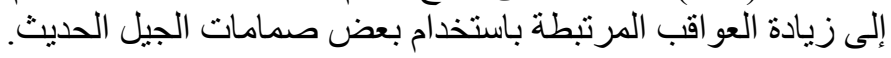

الهدف من الدراسة: لتحديد التنبؤات التى تؤدى لحدوث اضطر ابات فى التوصيل الكهربائى بالقلب بعد زر ع الصئمام الاورطى بالقسطرة.

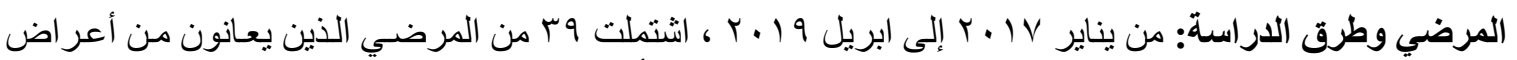

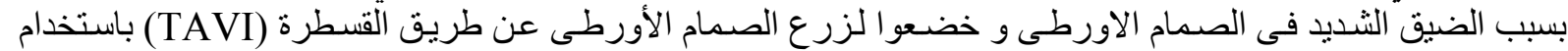

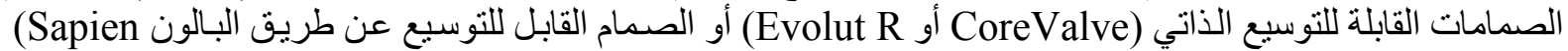

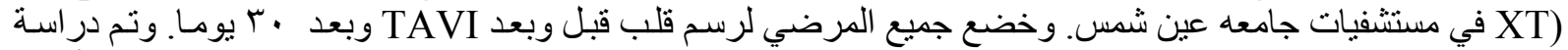

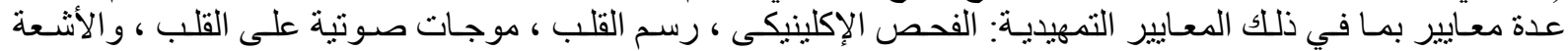

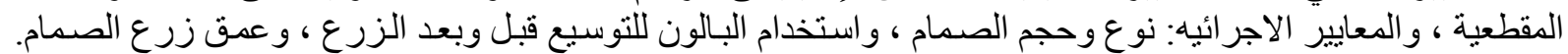
وقد تم وضع سطح الجسم فى الإعتبار بالنسبة لجميع المعايير الكمبة.

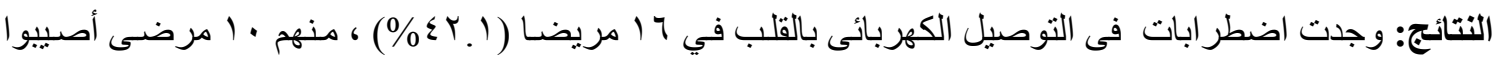

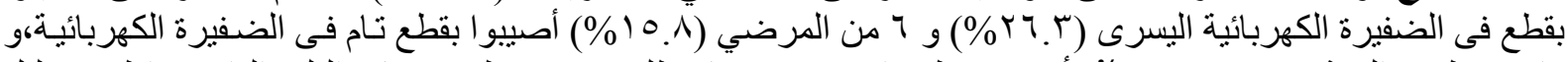

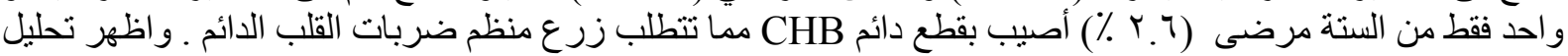

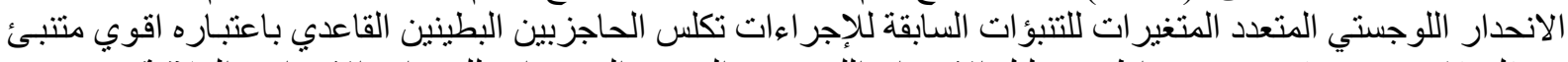

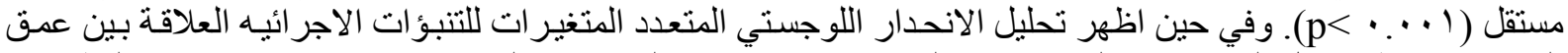

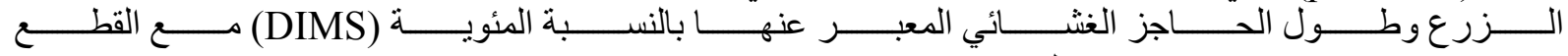

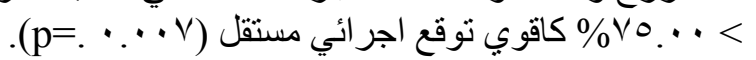

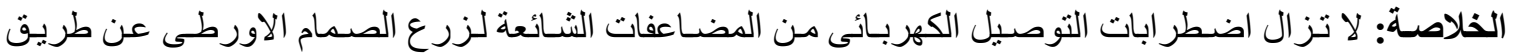

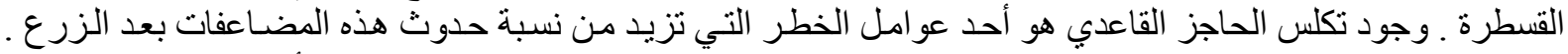
و العلاقة بين عمق الزر عرد وطول الحاجز الغشائي هو مؤشر اجر ائي مستقل قوي وهنالك حاجه إلى تأكيد النتائج عن طريق لزيق در اسات أخرى. 